\title{
Ecosystem models clarify the trophic role of whales off Northwest Africa
}

\author{
Lyne Morissette ${ }^{1,2, *}$, Kristin Kaschner $^{3}$, Leah R. Gerber ${ }^{2}$ \\ ${ }^{1}$ Institut des sciences de la mer de Rimouski, 310, Allée des Ursulines, C.P. 3300, Rimouski, Quebec G5L 2Y9, Canada \\ ${ }^{2}$ School of Life Sciences, Arizona State University, Box 874501 Tempe, Arizona 85287-4501, USA \\ ${ }^{3}$ Evolutionary Biology \& Ecology Lab, Institute of Biology I (Zoology), Albert-Ludwigs-University Freiburg, Germany
}

\begin{abstract}
There is global concern about the interaction between whales and fisheries, and in some countries, great whales are viewed as a threat to fisheries by potentially eating fish species that could be exploited for human consumption. We developed an ecosystem model to explore the trophic interactions between cetaceans and fisheries off Northwest Africa and to examine the potential impact of a reduction in the abundance of baleen whales on fishery yields. This allowed us to characterize the structure and function of the ecosystem in terms of biomass, mortalities, consumption rates, food habits, and fisheries. Faced with sparse data for our study area, we explicitly accounted for uncertainty in ecosystem structure, model accuracy, and input data and conducted an extensive sensitivity analysis. We tested model performance with time series of biomass and catches for important species of the system. Our results indicate that the overlap between prey species consumed by cetaceans and species targeted in fisheries is low. Furthermore, for a wide range of assumptions about whale abundances, diet composition, and food consumption in breeding areas, we found that whale consumption is several orders of magnitude lower than total fishery catches and 2 orders of magnitude lower than the amounts taken by other trophic groups. Finally, simulations of substantial reductions of whale populations did not influence the biomass of commercially important fish, nor any other species of the foodweb. These results suggest that fisheries yields would not benefit from the removal of whales in this area.
\end{abstract}

KEY WORDS: Competition · Ecopath with Ecosim $\cdot$ Cetaceans $\cdot$ Predation $\cdot$ Trophic impacts $\cdot$ Marine mammal-fisheries interactions $\cdot$ Ecosystem modeling

Resale or republication not permitted without written consent of the publisher

\section{INTRODUCTION}

In recent years, there has been much debate about the potential impacts of large whales on marine ecosystems (Clapham et al. 2007, Corkeron 2009, Gerber et al. 2009), and it has been proposed that whales play an important role in the worldwide decline of fisheries resources (e.g. Komatsu \& Misaki 2003). It has been implied that the amounts of fish eaten by whales represent a surplus resource that would be directly available for human consumption if cetacean numbers were to be reduced. However, the validity of such arguments is questionable in light of documented overfishing occurring on a global scale (Pauly et al. 2002, Myers \& Worm 2003), the lack of scientific evidence for existing large-scale competition between marine mammals and fisheries (Kaschner 2004, Morissette 2007), and the unpredictable consequences of culling (Paine et al. 1998, Scheffer et al. 2001). Nonetheless, the 'whales eat fish' issue has become a significant point of contention at recent International Whaling Commission (IWC) meetings.

Little is known about the ecological consequences of the removal of whales in terms of their past roles as consumers in food chains and as prey and carrion (Katona \& Whitehead 1988, Weslawski et al. 2000, Springer et al. 2003). Evidence suggests that ocean ecosystems have experienced a dramatic shift in structure as a result of the removal of large whales as well as extensive fishing activities (Pauly et al. 2002), 
including the area off Northwest Africa (Chavance et al. 2004). To understand the impact of whales on commercial fisheries, it is necessary to analyze the situation in an ecosystem context to account for the large number of indirect and direct interactions through which these 2 groups might influence each other (Bax 1998, IWC 2004, Morissette et al. 2006). Although competition between cetaceans and fisheries might occur in areas that represent important cetacean feeding grounds (Folkow et al. 2000, Kaschner 2004), when complex trophic interactions are taken into consideration, culling of marine mammals does not always benefit the fish stocks (Punt \& Butterworth 1995, L. Morissette et al. unpubl.). By feeding on other species that could be competing with fisheries, marine mammals and other high-level predators may actually increase fisheries yield (Punt \& Butterworth 1995, Gerber et al. 2009), or benefit other species of the foodweb (Bax 1998, Morissette et al. 2006, Anderson \& Lovvorn 2008). In contrast, the effects of fishing can be intensified by the removal of large whales (Estes et al. 2007). Only by considering all possible direct and indirect trophic linkages can the effect of the partial or complete removal of large whales on current fisheries yields be reliably assessed.

Food security issues are crucial in African countries (IWC 2008). With a coast of more than 4000 km, Northwest African countries are particularly concerned about the future of their fisheries (Alder \& Sumaila 2004, Palomares \& Pauly 2004). Fish represent an important source of protein for the region, which has suffered from the same collapse seen elsewhere in the world (Pauly et al. 1998, Myers \& Worm 2003) and also faces issues of foreign fishing fleets now coming to exploit its resources (Pauly et al. 2003, Alder \& Sumaila 2004, Mora et al. 2009). This area also attracts large populations of whales that annually come to the warmer waters to breed, during about a third of the year (Rice 1998, Perrin et al. 2002). Given the large size and high concentration of these animals, it is understandable why locals see them as potential competitors for fish. However, it seems intuitive for scientists that whales do not impact fisheries in breeding areas, where these species are known to mostly fast while giving birth or mating. Reasons for fasting are unknown, but may be metabolic (Lockyer 1981), behavioral (Corkeron \& Connor 1999), or thermodynamic (Brodie 1977) in nature. Nonetheless, the 'whales eat fish' issue has become very relevant in the policy management context in many tropical areas (Busby 2004, Gerber et al. 2009), including Northwest Africa. In that region, African members of the IWC commented on the 'natural competition existing between the whale species and the inhabitants of developing countries in the use of living marine resources (...) and the negative effects of a total protection of whale stocks to the detriment of food safety' (IWC 2008).

This major political issue in Northwest Africa justifies a concentrated effort to investigate the scientific basis for the debate. Here we examined the scientific evidence for the assertion that commercial fisheries are negatively impacted by whales off the coast of Northwest Africa. Our approach was to develop a trophic model describing the overall structure and function of the Northwest African marine ecosystem, and to analyze in detail the ecological role of marine mammals and their interaction with fishing activities using several ecological metrics. To incorporate the possibility for unusual feeding events, we considered a range of scenarios for whale biomass, feeding rates, and the trophic levels that are targeted by whales.

\section{MATERIALS AND METHODS}

Study area and cetacean species. Our study area is located off the coast of Northwest Africa, bounded by Morocco, Mauritania, Senegal, Guinea-Bissau, the Canary Islands (Spain), Gambia, Cape Verde, and Western Sahara (Fig. 1), covering latitudes from $8.5^{\circ}$ to $35.97^{\circ} \mathrm{N}$, and longitudes from $30^{\circ}$ to $6.5^{\circ} \mathrm{W}$, for a total area of 3.6 million $\mathrm{km}^{2}$ (Fig. 1). This area is characterized by the presence of the Canary Current, which flows along the African coast from north to south between $30^{\circ}$ and $10^{\circ} \mathrm{N}$ and offshore to $20^{\circ} \mathrm{W}$ (Fedoseev 1970). As a consequence, one major characteristic of this ecosystem is that it shows a major upwelling and other seasonal nutrient enrichments. Such seasonal environmental factors are the primary force driving the dynamics of this ecosystem, with intensive fishing as the secondary driving force (Bas 1993).

Baleen whales occurring in substantial biomass include minke Balaenoptera acutorostrata, sei $B$. borealis, fin B. physalus, Bryde's B. brydei, and humpback Megaptera novaeangliae whales. For species such as minke, fin, and possibly sei whales, the low latitudes of our focal area likely represent the extreme limits of their equator-bound breeding migrations (Rice 1998). Other baleen whales such as blue whales $B$. musculus are known to be present, but are likely to be less abundant (Branch et al. 2007). In terms of biomass, sperm whales Physeter macrocephalus are probably the most important toothed whale species. Other odontocete species include killer whales Orcinus orca and beaked whales (such as Mesoplodon densirostris, M. europaeus, and Ziphius cavirostris). There are also communities of small delphinids, composed of the following species: Delphinus delphis, Feresa attenuata, Globicephala macrorhynchus, Grampus griseus, Kogia brevi- 
ceps, K. simus, Lagenodelphis hosei, Peponocephala electra, Pseudorca crassidens, Sousa teuszii, Stenella attenuata, S. clymene, S. coeruleoalba, S. frontalis, S. longisrostris, Steno bredanensis, and Tursiops truncatus.

Ecosystem modeling approach. Ecopath model: We used Ecopath with Ecosim (EwE) to build a foodweb model of Northwest African waters. EwE is a widely used software program that provides a dynamic capability for exploring past and future impacts of fishing and environmental disturbances as well as for exploring optimal fishing policies (fully described by Christensen et al. 2005). We chose $E w E$ because of its representation of predator-prey interactions and the inclusion of different routines to take account of the estimation uncertainty associated with model inputs (Christensen \& Walters 2004, Plagányi \& Butterworth 2004).

Our foodweb model was based on the Senegambian model of Samb \& Mendy (2004) and was completed with information from 6 other models for the area: Cape Verde (Stobberup et al. 2004), Gambia (Mendy 2004), Guinea (Diallo et al. 2004), Guinea-Bissau (Amorim et al. 2004), Mauritania (Sidi \& Guénette 2004), and Morocco (Stanford et al. 2001). Species relevant to IWC discussions or with a distinctly different diet than other species were assigned to a unique trophic group (e.g. all baleen whales including minke, fin, humpback, sei, Bryde's, blue, and sperm whales but also killer whales), and other species were included as aggregated groups (i.e. beaked whales or dolphins). The model also included 17 trophic groups representing fish, cephalopods, crustaceans, benthic invertebrates, plankton, and detritus. For all groups, the biomass, production, consumption, and diet information were taken from the earlier Senegambian model (Samb \& Mendy 2004), or averaged from the 6 other areas where an $E w E$ model was available. Data descriptions for the whole model can be found in Morissette et al. (2009), and Table S1 in the supplement at www.int-res.com/articles/suppl/m404p289_ app.pdf represents a summary of input parameters and their relative uncertainty. In addition, we convened a regional workshop in Northwest Africa to access local data resources and expertise and to gain feedback from scientists and other local stakeholders that allowed us to improve our model (Morissette et al. 2009).

Ecosim calibration and analyses: We used Ecosim, the temporal simulations tool of $E W E$, to estimate biomass fluxes and to assess the changes in fish biomass when removing whales from the ecosystem. Ecosim builds on the Ecopath model and calculates the temporal changes in biomass for each trophic group using a set of differential equations. The particularity of this model is that it is based on the 'foraging arena theory'

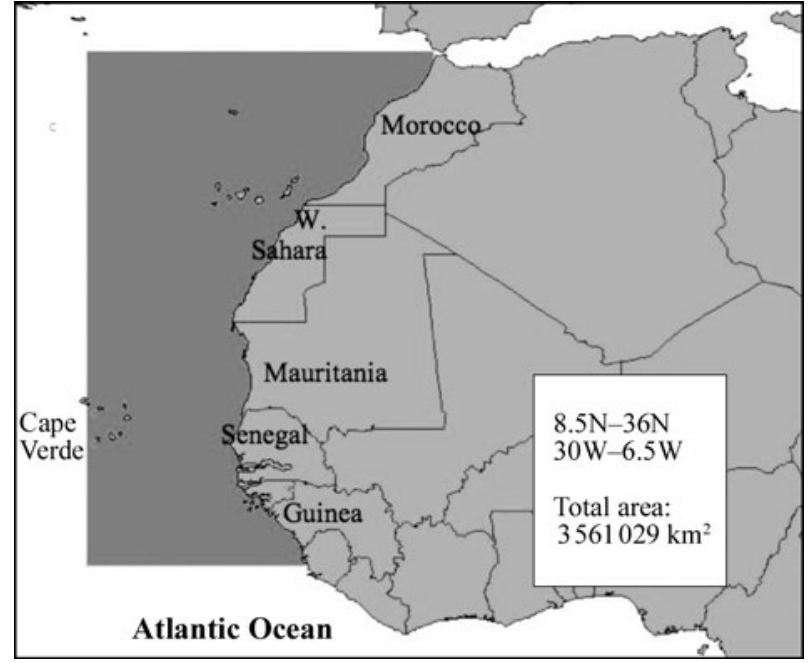

Fig. 1. Spatial boundaries of our study area. The coordinates of the Northwest African area are $8.5^{\circ}$ to $36^{\circ} \mathrm{N}$ and $30^{\circ}$ to $6.5^{\circ} \mathrm{W}$, covering a total area of approximately 3.6 million $\mathrm{km}^{2}$

(Walters et al. 1997), which assumes that predator and prey behaviors cause partitioning of prey populations, which are either available or unavailable to predators (which is reflected by the vulnerability parameter, $v$ ), and that there is continuous change between these 2 stages for any given potential prey, whether it is hiding from predation in some refuge or is out to feed. Using default values for $v$ has strong implications for assumptions about species abundance relative to their carrying capacity. Basically, it assumes that each group can at most increase the predation mortality it imposes on its prey with a factor of 2.0 (the default $V$ value). A lower value implies a donor-driven density-dependant interaction. On the other hand, a higher value involves a predator-driven density-independent interaction, in which predation mortality is proportional to the product of prey and predator abundance (i.e. LotkaVolterra). This implies a high flux rate for prey species in and out of vulnerable biomass pools. To account for differences in catchability of different trophic groups, we adjusted vulnerability settings based on available information about the specific ecology of each species and by fitting to time series of biomass for each group for which this information was available.

Time series of fishing effort were available for most commercially important trophic groups (bathydemersal predators, sharks, rays, coastal demersals, clupeids, and cephalopods) for the 1986 to 2007 period, and were used to drive the model. The model's projections were fitted to time series of observed biomass (absolute biomass data obtained from surveys) for the same trophic groups, and the same period. Details about fishing effort, catch, and biomass time series are covered in a data report by Morissette et al. (2009). 
Once we found the best fitted model based on these adjustments (the model for which predictions were the most closely related to observed values), we used this 'best possible model' to apply an extreme exploitation pattern that generated a dramatic increase in cetacean mortality to simulate the removal of whales from the ecosystem. Subsequently we compared biomass trends during a 22 yr simulation (1986 to 2007) before and after the removal of whales.

Input parameters for the model. Our preliminary results, along with data collected for the model, were presented at a regional workshop held in Dakar in May 2008 titled 'Whales and fish interactions: are great whales a threat to fisheries?', during which we sought local expertise and additional data sources to groundtruth and validate our model.

Cetacean groups: Reliable abundance estimates are lacking for almost all cetacean species in Northwest Africa. Estimates of local abundance were therefore based on the proportion of the global estimated abundance of each species that fell within the study area weighted by the relative suitability of the habitat in each of the study areas for each species (Kaschner 2004). Density estimates derived this way were ground-truthed using survey data from surveys conducted in the vicinity of our study areas or in similar types of habitat to the extent possible (Morissette et al. 2009).

For baleen whales, daily food intake was estimated based on a model by Armstrong \& Siegfried (1991) for food consumption by minke whales in the Antarctic. For all other cetaceans, we used an empirical model developed by Trites et al. (1997). Annual food consumption by each cetacean species was then divided by the biomass estimates in order to estimate consumption to biomass (Q/B) ratios used in the Ecopath model (Morissette et al. 2009).

In the context of our analysis, it is important to note that Northwest African waters represent a tropical breeding environment for most baleen whales (Sergeant 1969, Corkeron \& Connor 1999, Jann et al. 2003). Indeed, except for Bryde's whales, which are known to occur in these areas year round, baleen whales only spend about a third of the year in their breeding grounds, where they are known to either fast or eat at a considerably reduced rate (Lockyer 1981, Kenney et al. 1997, Perrin et al. 2002). In order to represent these migration patterns, biomass estimates were calculated according to the time spent in the area. Similarly, consumption rates also represent the migration of cetaceans, since we considered part of their diet to be imported (Morissette et al. 2009), and set the Ecosim parameters to represent this phenomenon as well. It has been difficult to quantitatively assess food intake in breeding areas, but the average has been estimated to be at most $10 \%$ of food intake in feeding grounds (Lockyer 1981).

We found very few quantitative descriptions of diet for cetaceans in general, especially in tropical areas such as Northwest Africa. Therefore, we mostly relied on published diet information for these cetaceans in the North Atlantic. A complete description of diet sources is given by Morissette et al. (2009).

Fisheries catch data time series: Fisheries catch data for Northwest Africa were obtained from the Sea Around Us database (Sea Around Us 2008). Time series of annual total catches taken between 1987 and 2004 were specified by the respective countries fishing in the area and by the taxa that were taken. We categorized taxa into different functional groups using available information about life history, ecology, and habitat preferences of the taxa. Catches were then divided into local and foreign fisheries. Local fisheries were defined as all countries bordering on our study area, regardless of whether catches were taken within each country's exclusive economic zone (EEZ) waters or in adjacent waters. All other fishing countries were defined as foreign fleets. Additional details can be found in Morissette et al. (2009).

Analyses and simulations. Comparison of diets and total intakes: Diet composition of cetacean species and fisheries catches were standardized to express diets and catches as proportions of each of the 27 trophic groups in our Ecopath model. Diet and catch composition were then compared between cetaceans and fisheries. Similarly, Ecopath allowed us to calculate the total consumption by cetaceans as an annual rate, which could then be compared to fisheries catch rates.

Overlap estimates: We calculated the extent of overlap in terms of resource use between different cetacean functional groups and fisheries. The assessment of overlap between marine mammal food consumption and fisheries catches was performed using a modified version of an ecological niche overlap index (Morissette 2007, after Kaschner 2004). This index scales from 0 (no overlap) to 0.250 (identical resource), and is calculated as:

$$
\alpha_{f, m}=\left(\frac{2 \cdot \sum_{k}\left(p_{m, k} \cdot p_{f, k}\right)}{\sum_{k}\left(p_{m, k}\right)^{2}+\sum_{k}\left(p_{f, k}\right)^{2}}\right) \cdot\left(\frac{Q_{m}}{\left(Q_{m}+C_{f}\right)} \cdot \frac{C_{f}}{\left(Q_{m}+C_{f}\right)}\right)
$$

where $\alpha_{f, m}$ is the quantitative overlap between a fishery $f$ and a marine mammal group $m$ in the ecosystem, and the first term expresses the qualitative similarity in diet/catch composition between the marine mammal group $m$ and fisheries $f$ sharing the resource or food type $k$, with $p_{m, k}$ and $p_{f, k}$ representing the proportions of group $k$ in the diet of marine mammals $m$ or the catch by fishery $f$. This term is multiplied by the product of the proportion of total food consumption by 
marine mammals $Q_{m}$ and the proportion of total fisheries catches $C_{f}$ in the ecosystem. This index scales from 0 (no overlap) to 0.250 (identical resources targeted by whales and fisheries). When resource use is identical between these 2 groups, the first term of Eq. (1) is equal to 1 and each proportion of the second term is 0.5 (or 0.25 for the product).

Ecosystem indices: We used the mixed trophic impact (MTI) routine of Ecopath to assess the direct and indirect interactions between species in the ecosystem. This routine quantitatively synthesizes both the direct and indirect effects that a small change in the biomass of a group will have on the biomass of all other groups in a system (Ulanowicz \& Puccia 1990):

$$
\mathrm{MTI}_{i j}=\mathrm{DC}_{i j}-\mathrm{FC}_{j, i}
$$

where $\mathrm{DC}_{i j}$ is the diet composition term expressing how much $j$ contributes to the diet of $i$, and $\mathrm{FC}_{j, i}$ is a host composition term giving the proportion of the predation on $j$ that is due to $i$ as a predator. When calculating the host compositions, the fishing fleets are included as 'predators.'

When calculating the MTI of each trophic group, the fishing fleets were also included as predators. Beneficial predation was calculated as the percentage of the overall trophic impact by cetaceans that is positive for any prey group of this predator (Morissette 2007).

Similar to what is available for the trophic level of the catch $\left(\mathrm{TL}_{\mathrm{C}}\right.$, Christensen et al. 2005), we calculated the trophic level of consumption $\left(\mathrm{TL}_{\mathrm{Q}}\right)$ by cetaceans using Morissette (2007). This TL value represents the average trophic level of all trophic groups consumed or caught, weighted by their importance in the diet or the catch, and is calculated as:

$$
\mathrm{TL}_{\mathrm{Q}}=\sum_{i}\left(\mathrm{TL}_{i} \cdot\left(\frac{\sum_{j=1}^{n} Q_{i j}}{\sum_{j=1}^{n} Q_{j}}\right)\right)
$$

where $Q_{i j}$ is the consumption of prey $i$ (in tons) by cetacean $j, Q_{j}$ is the total consumption of all species by cetacean $j$, and $\mathrm{TL}_{i}$ is the trophic level for species $i$. Eq. (3) represents the average trophic level on which cetaceans feed, i.e. the average TL of each species, multiplied by its proportion in the consumption matrix ( $\mathrm{km}^{-2} \mathrm{yr}^{-1}$ that cetaceans consume).

Finally, the primary production required (PPR) to sustain fisheries was compared to the PPR to sustain cetacean groups. This parameter was directly calculated by Ecopath (Christensen et al. 2005).

Uncertainty. External validation/fitting to real time series data: The model was fitted to time series by adjusting different parameters in Ecosim. We first modified the maximum relative feeding time from 2.0 (default) to 10.0 for all cetaceans, considering that these species can spend more time searching for their prey if they are scarce. Feeding time adjustment rate was set to 0.5 for cetaceans and to 0.0 for other groups, because cetaceans may change their feeding time as food availability varies. Finally, assuming that cetaceans can be opportunistic feeders and adapt their diet depending on prey availability, the switching power was set to 2.0 for these groups and left to 0.0 (default) for other trophic groups. The model was driven by fishing efforts where available, and by fishing mortalities for other groups. If information was not available, we forced the model to fit the catch and biomass time series. Fishing effort was used as a driving force for the model.

Using available time series of effort, biomass, and catch that we collated from the literature and from the Sea Around Us database, we validated our results fitting the model's dynamic behavior to independent time series of catch or biomass data (Christensen et al. 2005). Such fitting of time series allowed us to compare how the model replicates observed behavior through time.

Sensitivity analyses: We conducted an extensive sensitivity analysis to test the robustness of our results to different assumptions and model parameters. In order to test the model's performance, we used the Monte Carlo tool in Ecosim to vary Ecopath's biomass parameters for whales and fish groups. For this sensitivity analysis, cetacean groups were allowed to vary $\pm 1000 \%$ from their Ecopath biomass values, and the Monte Carlo was drawn from a uniform distribution. This routine allowed us to test the sensitivity of initial biomass parameters and generate error estimates for predictions. In addition, we used different scenarios to explore the impacts of changing assumptions about feeding rates, biomass, and diet of the cetacean groups in our model (Table 1), to see if these alternative scenarios represent a better model fit (defined as a decrease in the sum of squares relative to the fit to observed data).

\section{RESULTS}

\section{Comparison of diets and total intakes}

While cetaceans consumed a variety of different prey groups (mainly zooplankton, other coastal pelagic, clupeid, bathydemersal, mesopelagic, and coastal demersal fishes), more than $75 \%$ of the catches from local fleets in Northwest Africa were composed of 4 prey groups: clupeids, other coastal pelagics, coastal demersals, and cephalopods. Foreign fleets were even less diversified, with clupeids and other coastal pelag- 
Table 1. Uncertainty analyses and different scenarios tested

\begin{tabular}{|llcl|}
\hline Scenario & \multicolumn{1}{c|}{ Parameter } & $\begin{array}{c}\text { Default (best model) } \\
\text { setting (\%) }\end{array}$ & \multicolumn{1}{c}{ Type of change } \\
\hline 1 & Feeding rate for baleen whale species & 10 & Increased to $50 \%$ feeding rate \\
2 & Cetacean biomass & 100 & Increased to $1000 \%$ \\
3 & Fish biomass & 100 & Decreased to $10 \%$ \\
4 & Cetacean diet: \% of higher trophic & Based on available & Doubled proportion of higher trophic level \\
& level fish & diet info & fish and adjusted the remaining diet proportions \\
\hline
\end{tabular}

ics alone representing more than $75 \%$ of their catch (Fig. 2).

When comparing the total annual amounts of each prey group taken by either cetaceans or fisheries (Fig. 3), we found that, except for mesopelagics, cephalopods, and zooplankton, the fisheries catches were always substantially larger than what was eaten by cetaceans. Fisheries catches of commercially important species such as coastal demersals, clupeids, other coastal pelagics, and coastal tunas were an order of magnitude higher than the amounts consumed by cetaceans (Fig. 3). The highest discrepancy between cetacean consumption and the fisheries catch was estimated for large pelagics, where the fisheries catch was 50 times more $\left(0.0127 \mathrm{t} \mathrm{km}^{-2} \mathrm{yr}^{-1}\right)$ than the amount consumed by cetaceans $\left(0.0003 \mathrm{t} \mathrm{km}^{-2}\right.$ $\left.\mathrm{yr}^{-1}\right)$. Finally, some prey groups, such as sharks, rays, and coastal tunas, are exclusively targeted by fisheries and not consumed by cetaceans.

In Northwest Africa, the total catch of marine organisms is $0.516 \mathrm{t} \mathrm{km}^{-2} \mathrm{yr}^{-1}$. In comparison, the consumption of commercially exploited biomass by all cetaceans $\left(0.334 \mathrm{t} \mathrm{km}^{-2} \mathrm{yr}^{-1}\right)$ is nearly two-thirds the amount caught by fisheries (Table 2). When examined on a species by species group, the amount consumed by each group of cetaceans is about 2 orders of magnitude lower than what is caught by fisheries, except for the dolphin group, which consumes about $40 \%$ of what is caught by fisheries (Table 2).

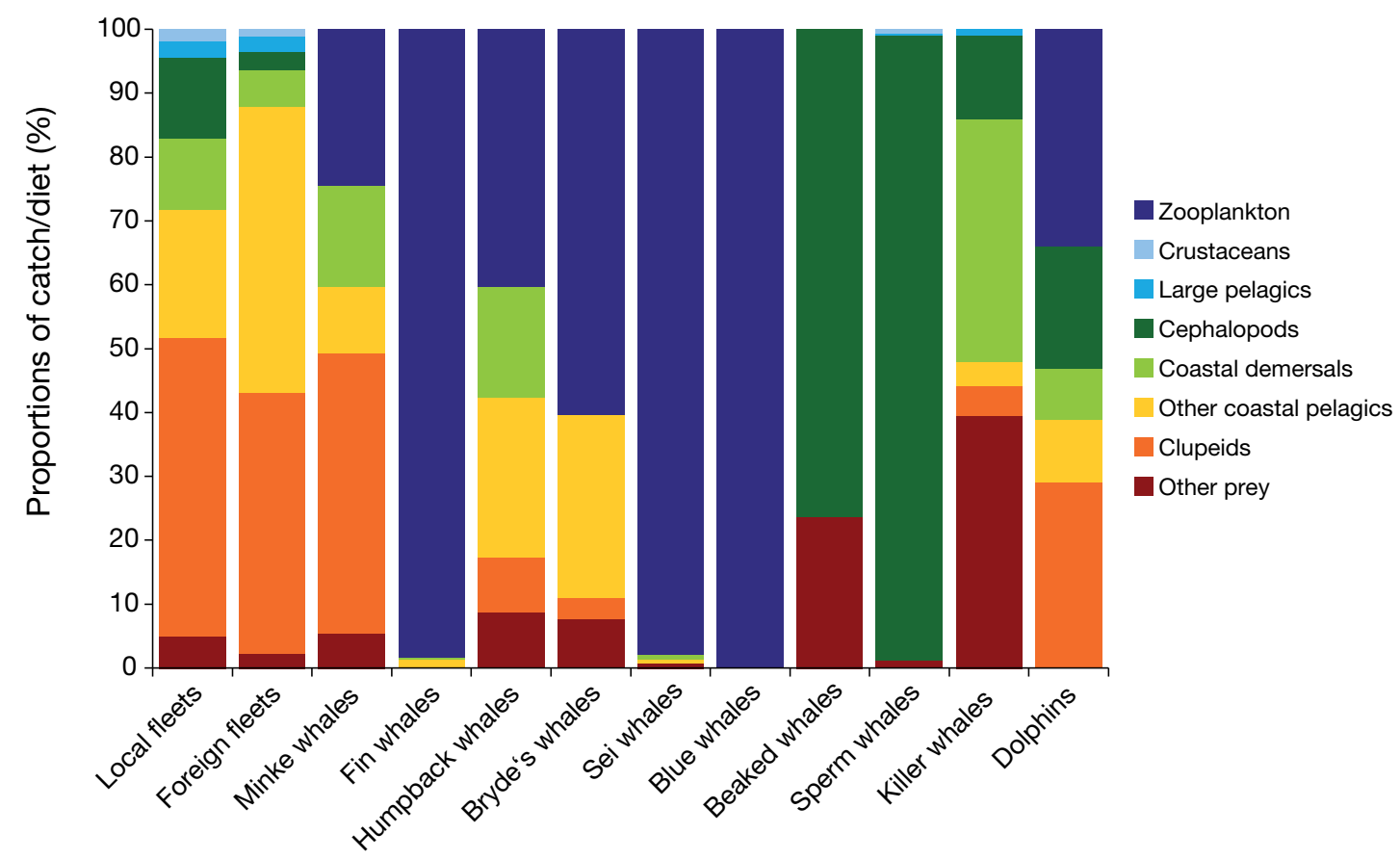

Fleet \& cetacean groups

Fig. 2. Comparison of proportional diet compositions of different cetacean groups (\% weight of prey) and catch composition of different fishing fleets (\% caught species, in weight). 'Other prey' include dolphins, mesopelagic fish, bathydemersal predators, sharks, rays, coastal tunas, and benthic organisms. Warm colors (red, orange) represent fish that are mainly targeted by fisheries, while cool colors (green, blue) are prey essentially eaten by whales 


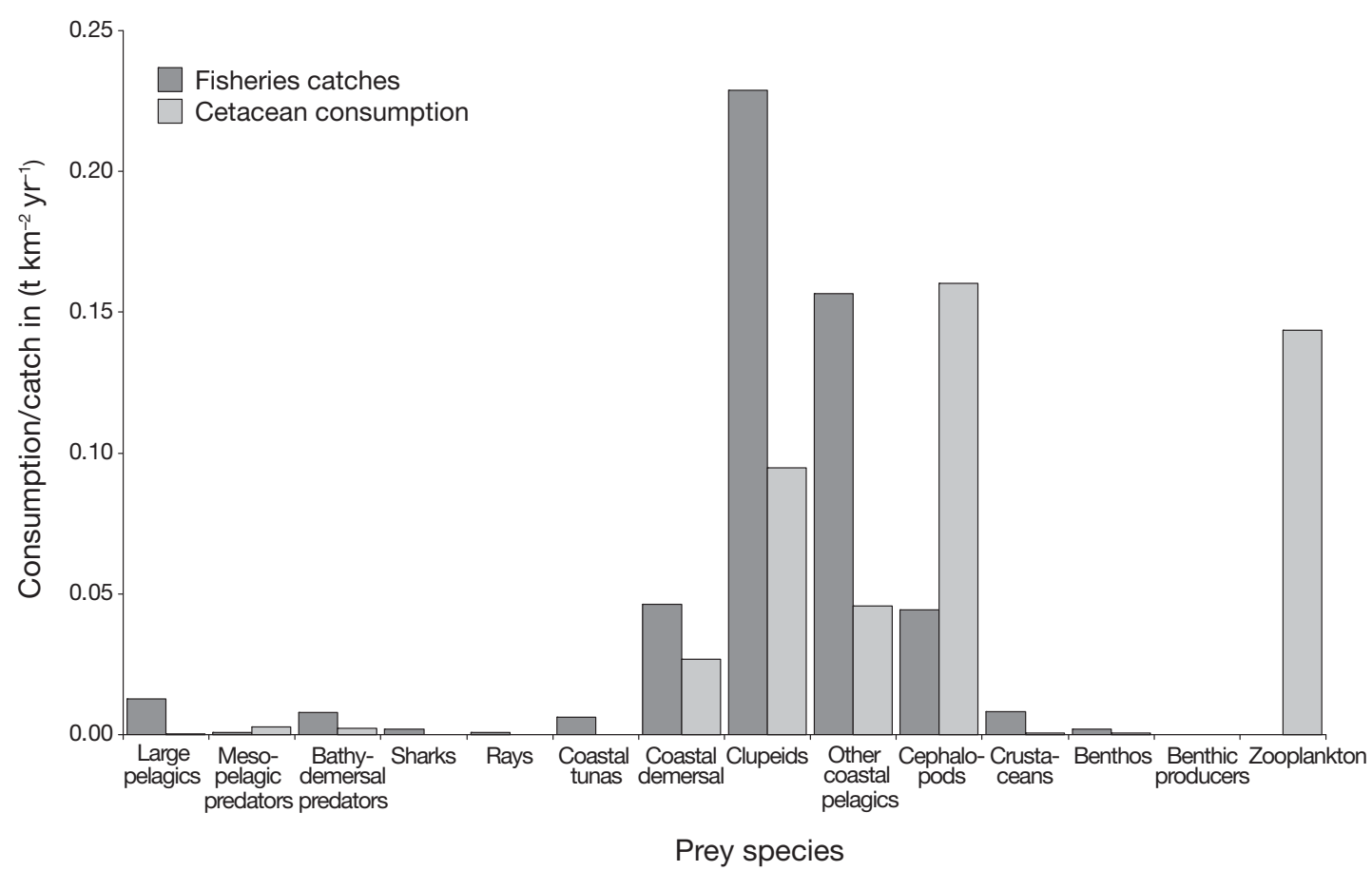

Fig. 3. Comparison of total annual fisheries catches and cetacean consumption, per trophic group off Northwest Africa

Table 2. Resource overlap index, consumption $(Q)$ of exploitable biomass $\left(\mathrm{t} \mathrm{km}{ }^{-2}\right)$, mean trophic level of the catch or cetacean consumption $\left(\mathrm{TL}_{\mathrm{C}}\right.$ and $\mathrm{TL}_{\mathrm{Q}}$ i weighted average trophic level of all trophic groups caught or consumed), and primary production required (PPR) for fisheries' catches and cetacean consumption off the coast of Northwest Africa

\begin{tabular}{|c|c|c|c|c|c|}
\hline & $\begin{array}{c}\text { Overlap } \\
\text { index }\end{array}$ & $\begin{array}{c}Q \text { of } \\
\text { exploitable } \\
\text { biomass }\end{array}$ & $\begin{array}{l}\mathrm{TL}_{\mathrm{C}} \\
\mathrm{TL}_{\mathrm{Q}}\end{array}$ & PPR & $\begin{array}{c}\text { PPR } \\
(\% \text { of } \\
\text { total PP) }\end{array}$ \\
\hline Fisheries & - & 0.516 & 2.80 & 62.38 & 0.29 \\
\hline Minke whales & 0.011 & 0.005 & 2.55 & 2.36 & 0.01 \\
\hline Fin whales & $<0.001$ & $<0.001$ & 2.02 & 0.06 & $<0.01$ \\
\hline Humpback whales & 0.001 & 0.001 & 2.41 & 0.07 & $<0.01$ \\
\hline Bryde's whales & 0.021 & 0.020 & 2.39 & 51.01 & 0.23 \\
\hline Sei whales & $<0.001$ & $<0.001$ & 2.00 & 0.04 & $<0.01$ \\
\hline Blue whales & 0.018 & $<0.001$ & 2.00 & 0.01 & $<0.01$ \\
\hline Beaked whales & 0.001 & 0.001 & 3.20 & 22.14 & 0.01 \\
\hline Sperm whales & $<0.001$ & 0.101 & 3.12 & 0.04 & 0.10 \\
\hline Killer whales & $<0.001$ & 0.001 & 2.93 & 28.56 & 0.13 \\
\hline Dolphins & 0.153 & 0.204 & 2.54 & 28.18 & 0.13 \\
\hline Baleen whales & 0.029 & 0.026 & 2.37 & 54.18 & $<0.01$ \\
\hline All cetaceans & 0.134 & 0.334 & 2.65 & 134.95 & 0.01 \\
\hline
\end{tabular}

\section{Overlap estimates}

Overlap in resource exploitation between fisheries and the cetacean species was very low in Northwest Africa (Table 2). In comparison to other ecosystems (L. Morissette et al. unpubl.), the overlap between baleen whales and fisheries in Northwest Africa was minimal, with a value of 0.029. Fisheries in the region mainly targeted clupeids, other coastal pelagics, cephalopods, and large pelagics (close to $90 \%$ of total landings). Except for minke whales that feed on clupeids and coastal demersal fish (and showed the largest overlap for a baleen whale species), all other baleen whales mainly feed on zooplankton, and thus showed very little overlap with fisheries. When all cetaceans were included, the overlap of 0.134 was mainly driven by the similarity between dolphin diets and fisheries catches, which both target primarily clupeids and cephalopods. Even considering the overlap index of all cetaceans, the result is still below the global average of overlap calculated for 7 marine ecosystems (L. Morissette et al. unpubl.).

\section{Ecosystem indices}

The MTI of cetaceans and fisheries in the model of Northwest Africa indicated that both cetaceans and fisheries had an overall negative impact on all other species of the ecosystem (overall MTI for cetaceans = -0.04 ; overall MTI for local fleets $=-1.17$; overall MTI for foreign fleets $=-0.89$ ). The MTI of baleen whales 
Table 3. Mixed trophic impacts of fisheries, cetaceans, and only baleen whales on the different trophic groups of the Northwest Africa model. Negative values represent a negative impact, while positive values represent a positive impact

\begin{tabular}{|c|c|c|c|c|}
\hline \multirow[t]{2}{*}{ Impacted species } & \multicolumn{4}{|c|}{ Fisheries } \\
\hline & $\begin{array}{l}\text { Local } \\
\text { fleets }\end{array}$ & $\begin{array}{l}\text { Foreign } \\
\text { fleets }\end{array}$ & $\begin{array}{l}\text { Baleen } \\
\text { whales }\end{array}$ & $\begin{array}{c}\text { All } \\
\text { cetaceans }\end{array}$ \\
\hline Minke whales & 0.0013 & 0.0010 & 0.0000 & 0.0001 \\
\hline Fin whales & -0.0014 & -0.0012 & 0.0000 & 0.0000 \\
\hline Humpback whales & 0.0004 & 0.0001 & 0.0000 & 0.0000 \\
\hline Bryde's whales & -0.0017 & -0.0015 & -0.0007 & -0.0007 \\
\hline Sei whales & -0.0014 & -0.0013 & 0.0000 & 0.0000 \\
\hline Baleen whales & -0.0015 & -0.0013 & 0.0000 & 0.0000 \\
\hline Beaked whales & -0.0018 & 0.0037 & 0.0011 & -0.0069 \\
\hline Sperm whales & 0.0003 & 0.0070 & 0.0015 & -0.0091 \\
\hline Killer whales & 0.0084 & 0.0035 & -0.0001 & -0.0001 \\
\hline Dolphins & -0.0017 & 0.0031 & 0.0002 & -1.0012 \\
\hline Seabirds & 0.0256 & 0.0244 & -0.0003 & 0.0005 \\
\hline Large pelagics & 0.0048 & -0.0089 & 0.0025 & 0.0032 \\
\hline Mesopelagic predators & 0.0074 & 0.0083 & -0.0028 & -0.0042 \\
\hline Bathydemersal predators & -0.0107 & -0.0098 & 0.0001 & 0.0017 \\
\hline Sharks & -0.3694 & -0.0406 & 0.0001 & -0.0014 \\
\hline Rays & -0.1383 & -0.1205 & 0.0002 & -0.0017 \\
\hline Coastal tunas & -0.5036 & -0.5153 & 0.0003 & 0.0000 \\
\hline Coastal demersal & 0.0183 & -0.0011 & -0.0007 & 0.0040 \\
\hline Clupeids & 0.0278 & 0.0274 & 0.0005 & 0.0015 \\
\hline Other coastal pelagics & 0.0210 & 0.0184 & -0.0020 & -0.0015 \\
\hline Cephalopods & 0.0003 & 0.0072 & 0.0015 & -0.0093 \\
\hline Crustaceans & 0.0027 & 0.0048 & -0.0001 & -0.0018 \\
\hline Benthos & -0.0026 & -0.0027 & 0.0000 & 0.0009 \\
\hline Benthic producers & 0.0000 & 0.0000 & 0.0000 & 0.0000 \\
\hline Zooplankton & -0.0145 & -0.0130 & 0.0000 & -0.0003 \\
\hline Phytoplankton & 0.0000 & 0.0000 & 0.0000 & 0.0000 \\
\hline Detritus & 0.0000 & 0.0000 & 0.0000 & 0.0000 \\
\hline Local fleets & 0.0119 & 0.0114 & 0.0000 & -0.0003 \\
\hline Foreign fleets & 0.0140 & 0.0117 & -0.0006 & 0.0000 \\
\hline Overall impact & -0.9568 & -0.6458 & -0.0004 & -0.0089 \\
\hline
\end{tabular}

was 3 orders of magnitude smaller than the MTI from fisheries for any species (Table 3). The groups that were mostly impacted by cetacean consumption (all species included) were cephalopods and mesopelagic predators (Table 3). When only baleen whales were considered (Table 3), mesopelagic predators, coastal demersals, and other coastal pelagics were mostly impacted. In contrast to fisheries where this effect is negligible (Table 3), we found some cases of beneficial predation by cetaceans on species such as large pelagics, bathydemersal predators, sharks, rays, coastal tunas, coastal demersals, and clupeids. Similarly, consumption by baleen whales alone resulted in relatively large positive impacts for large pelagics, bathydemersal predators, clupeids, and cephalopods. Local and foreign fisheries seemed to benefit from the presence of killer whales in the ecosystem (MTI of 0.0039 and 0.0015 for killer whales on local and foreign fleets, respectively). The same MTI analysis for the local and foreign fisheries indicated they negatively impacted sharks, rays, and coastal tunas
(Table 3). Conversely, coastal demersals and clupeids were positively affected by fisheries.

In the Northwest African waters, baleen whales feed mainly on lower trophic level species than fisheries (Table 2). The only cetaceans feeding on higher trophic levels than fisheries were sperm whales $\left(\mathrm{TL}_{\mathrm{Q}}=3.12\right)$ and beaked whales $\left(\mathrm{TL}_{\mathrm{Q}}=\right.$ 3.21 ), both of which feed primarily on cephalopods (more than 90\% of their diet). In addition, $\mathrm{TL}_{\mathrm{Q}}$ of killer whales was higher than that of fisheries, since part of the diet of this species is composed of dolphins. However, baleen whales consistently feed on lower trophic levels (average $\mathrm{TL}_{\mathrm{Q}}=2.4$ ) than fisheries $\left(\mathrm{TL}_{\mathrm{C}}=2.8\right)$, and the largest discrepancy between $\mathrm{TL}_{\mathrm{Q}}$ and $\mathrm{TL}_{\mathrm{C}}$ was observed between fisheries and baleen whales or fin whales, where the $\mathrm{TL}_{\mathrm{C}}$ is about $40 \%$ larger than the $\mathrm{TL}_{\mathrm{Q}}$.

The PPR to sustain consumption by all cetacean species was lower than the PPR to sustain the fisheries (Table 2). In terms of percentage of the PPR, killer whales, dolphins, sperm whales, and Bryde's whales required the most primary production, but this was still on average $30 \%$ lower than the PPR for fisheries. Fin, humpback, sei, and blue whales had the lowest PPR (they required less than $1 \%$ of the total primary production of the system).

\section{Model fitting}

The vulnerability matrix for the Northwest African model was first parameterized using an automated vulnerability search routine available in Ecosim to first identify predator-prey interactions critical to model functioning (Christensen et al. 2005). The most influential predator groups in terms of their prey's vulnerabilities in our model tend to be minke whales, blue whales, large pelagics, sharks, and rays.

The resulting algorithm fitted the model to sharks, rays, coastal demersals, clupeids, and cephalopods (Fig. 4), but was poor for bathydemersal predator biomass. This can be explained by incomplete or incorrect fishing mortality rates used in Ecosim. Indeed, the simulated patterns for exploited species will obviously not track observed patterns if those patterns have been caused by fishing, if no reliable time series of fishing mortalities is available (Christensen et al. 2005). The assumption that we have made for this group is thus that the changes in biomass might be attributable pri- 

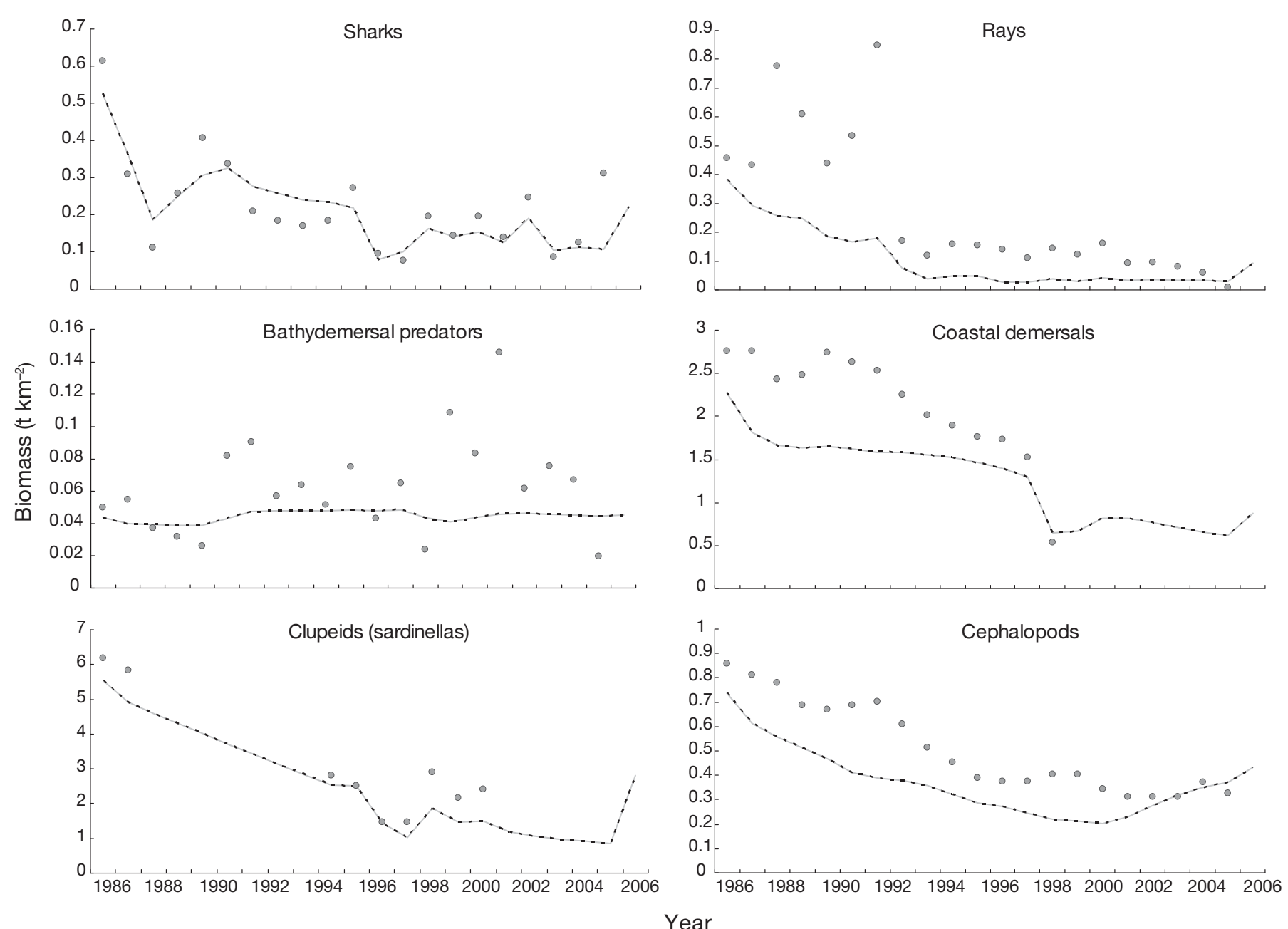

Fig. 4. Simulation of biomass changes for important fish groups after the removal of all baleen whales from the ecosystem of Northwest Africa. Grey lines represent biomass trends over 22 yr with cetaceans, while black dashed lines show the biomass trends after the removal of baleen whales - no differences are apparent. The time series of observed biomass data are also shown on the graph (०)

marily to trophodynamics and not to fishing. However, even when allowing the Monte Carlo tool to choose $1000 \%$ of initial biomass for marine mammals, the best fitting trial was the original model that we constructed.

\section{Dynamic simulations: exploring management scenarios}

We first ran the default Northwest Africa model with the real time series of fishing mortality $(F)$, and then compared the model's predictions when removing baleen whales. In general, after simulating baleen whale extirpation in the ecosystem, we found no substantial change in biomass of all prey species compared to the initial scenario with these whales included in the ecosystem (Fig. 5). Thus, using our 'best model' and including as many ecological details as possible, our results show that even a complete removal of baleen whales does not lead to a measurable increase in fish biomass (Fig. 5).

To investigate alternative management scenarios, we also conducted simulations that assumed substantial reductions in fishing effort of either foreign or local fleets. Reducing fishing effort for all commercially important species by $50 \%$ resulted in a reduction in total biomass in the ecosystem. This result reflects the complex dynamics of the system and the potentially counterintuitive interactions between all predators and prey. However, for some functional groups such as large pelagics, a reduction in fishing effort results in a higher biomass. Because this represents important top predators in the ecosystem $(\mathrm{TL}=3.31)$, such an increase is likely to create an increase in predation on the lower trophic levels. This may explain the overall decrease in biomass in the system under these as- 


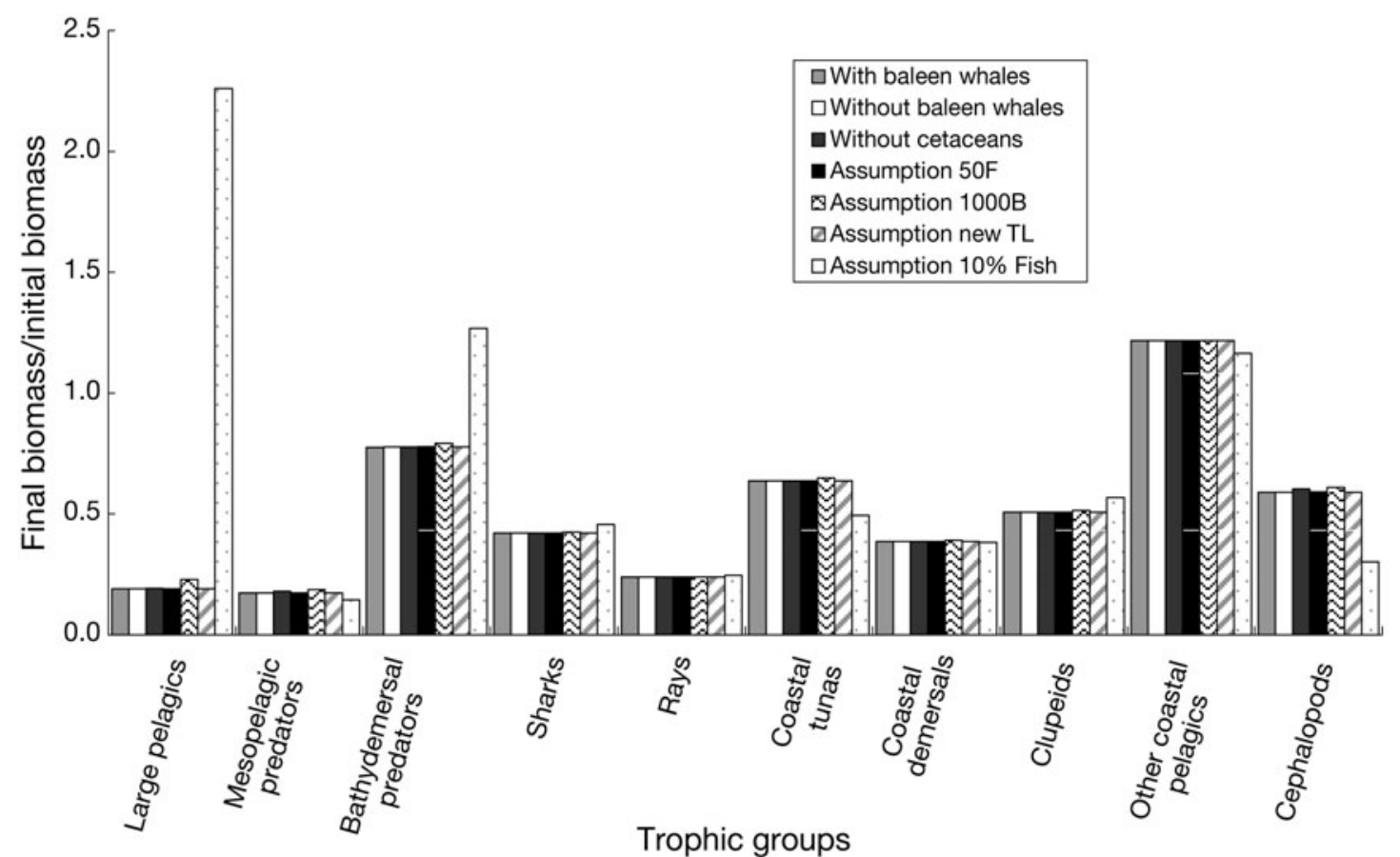

Fig. 5. Biomass change after a $22 \mathrm{yr}$ simulation in the Northwest African ecosystem, under different scenarios (outlined in Table 2): with all cetaceans (default), without baleen whales (simulating an eradication of only baleen whales), with no cetaceans at all (simulating a complete eradication of all cetacean species), assuming a $50 \%$ increase in fishing effort (50F), assuming increasing cetacean biomass by an order of magnitude (1000B), assuming cetaceans feed at a higher trophic level than initially expected (new TL), and assuming an increase of $10 \%$ in the biomass of all fish

sumptions. Conversely, a simulation with a fishing effort increased by $50 \%$ resulted in a decline in biomass for most commercially important species.

\section{Sensitivity analyses}

In order to incorporate uncertainty related to the ecology of cetacean species included in our models, we tested the effects of our assumptions by changing several key parameters. First, we tested our assumption of a $10 \%$ baleen whale feeding rate in breeding areas and the assumed transferability of diet composition based on information collected elsewhere. We therefore ran the model scenarios where we assumed a $50 \%$ feeding rate and accounted for the possibility that that cetaceans might feed on higher trophic levels in tropical areas than elsewhere (Scenario 1; Table 1). For both assumptions (10\% and $50 \%$ feeding rates), we only found a slight increase in biomass (less than $1 \%$ ) for large pelagics, mesopelagic predators, and bathydemersal predators after $22 \mathrm{yr}$. These are the only species for which we saw a positive change (Fig. 5).

Given the high level of uncertainty associated with our cetacean abundance estimates, we also tested the impact of substantial increases in cetacean biomass on model results (Scenario 2). Even with the unlikely but most extreme scenario of a $1000 \%$ increase, we found no effect on the biomasses of commercially important fish.

The assumption of a reduced fish biomass (Scenario 3) did not produce a better fit of the model (Fig. 4), but was the only one where we observed a response in fish biomass after the removal of baleen whales (Fig. 5). Indeed, this scenario created a noteworthy increase in biomass for large pelagics and bathydemersal predators after the removal of baleen whales. However, the same scenario also created the most drastic declines in mesopelagic predators and cephalopods (Fig. 5).

Under the assumptions of Scenarios 1 and 4, the MTI of baleen whales was still 2 orders of magnitudes lower than MTI of fisheries on any other trophic group in the ecosystem. Similarly, under Scenarios 2 and 3, the MTI of baleen whales was still 1 order of magnitude lower than the MTI of fisheries on any other trophic group in the model.

Overall, the different assumptions did not result in any substantial increase in commercially exploitable fish biomass after the removal of whales in the Northwest African ecosystem, except in 1 specific case, for 1 specific group: assuming a $10 \%$ reduction in the biomass of all fish would double the biomass of large pelagics after the eradication of whales in our model (Fig. 5). 


\section{DISCUSSION}

\section{Would the fisheries catch increase if whale populations were reduced?}

The role of cetaceans in ecosystems has received growing attention in recent years, and the application of models to investigate and understand the complexity of foodwebs and their dynamic interactions is becoming more frequent (Aydin \& Mueter 2007, Gerber et al. 2009). In a global assessment of the management effectiveness of fisheries, Mora et al. (2009) suggested that fisheries in the Northwest African region are not managed very well. At the same time, this area represents a major breeding ground, where large whales aggregate during winter after a long migration from the colder waters in which they feed. With their large size and high abundance, and now facing an important crisis in the management of their fisheries, it is understandable that local communities are concerned about whales and their potential competition with fisheries, and that imposing some sort of management to whale populations could help the depleted fish stocks to recover. However, our results suggest that, using a variety of indicators and for a wide range of model assumptions, whales have little impact on any component of the ecosystem, and reducing their abundance would not lead to an increase in fishery yield in Northwest African waters.

In fact, whales consume marine resources that are at a lower trophic level than what is caught for fisheries. The MTI analyses corroborate that the negative impacts of cetaceans were minimal on all commercially important fish groups, and that they even had a positive impact on major fish groups. Therefore, instead of representing a threat to fisheries, the presence of cetaceans (even including dolphins) can be somewhat beneficial to fleets fishing on large pelagics, bathydemersal predators, clupeids, and cephalopods, which represent the most commercially important fish groups of the Northwest African ecosystem.

In fact, cetaceans show only little overlap with fisheries and require less primary production than fisheries. Compared to other ecosystems (see Morissette 2007 for overlap, Pauly \& Christensen 1995 for PPR), the overlap of these marine mammals is also very low. Most of the overlap is due to dolphins, which also feed at higher trophic levels, and thus require more primary production to sustain their consumption. Interestingly, while there is an unjustified 'whales eat fish' issue in Northwest Africa, there is no 'dolphins eat fish' issue.

Finally, our modeling simulations showed that even under a wide range of assumptions on abundance, feeding rates, and diets, baleen whales are unlikely to affect any commercially important fish group in North- west Africa, even if they were totally eradicated from the system. Conversely, an increase in fishing by $50 \%$ (to compare to a $50 \%$ increase in cetacean consumption) created a major decrease in biomass for most fish groups in the system, suggesting that the ecosystem is currently heavily exploited and cannot sustain more fishing effort without collapsing. This is in line with what has been described in the literature for this area (Samb \& Mendy 2004, Mora et al. 2009).

The ecosystem modeling approach used here corroborates what was proposed by previous authors (Yodzis 2001, Kaschner 2004): baleen whales, despite their large size and their recurrent presence in tropical waters, only have a marginal effect on tropical ecosystems because they generally do not feed in these areas (Lockyer 1981).

Our results about the potential competition (or lack thereof) between whales and fisheries are specific to tropical waters. Due to complex ecosystem dynamics, it is far from clear whether there is a direct relationship between cetacean predation and loss to fisheries. Thus, even in areas for which there is competition, scientists remain doubtful that culling cetaceans would improve fishery yield (Yodzis 2001, Morissette 2007).

In a management context, the controversies that have led to the idea that reducing whale abundance will increase fishery yield have largely focused on tropical breeding areas. In light of the low relative abundance of whales and their low consumption rates in these areas, the removal of whales in these areas is unlikely to benefit fisheries.

\section{Strengths and weaknesses of our modeling efforts}

Geographically, as our study site coincides with low latitude breeding areas for baleen whales, we did not expect to find significant ecological interactions between whales and fisheries. Our goal was to use the best available scientific data and estimates of uncertainty in these data to understand the plausible range of potential interactions between whales and fisheries in this region. The 'whales eat fish' issue is directed towards many species of whales and the many different prey they feed on. Consequently, the debate is an ecosystem issue and is more complex than the simple predator-prey relationship. To address such an issue, it is thus crucial to consider indirect effects such as competition, mediation, or beneficial predation (Morissette et al. 2006) with ecosystem models, as pointed out at the IWC modeling workshop (IWC 2004).

This ecosystem model also helps to provide a general feel of the extent of interactions between whales and fisheries, identify major shortcomings in the data, and provide important reference points for more specific 
research in the Northwest African marine ecosystem. From a management point of view, knowing that impacting one group will cause changes in another can provide tools for long-term and multispecies management.

Important details were added in this study in order to address different caveats of the $E w E$ approach and the problems they pose when interpreting the results. First, we performed different levels of sensitivity analysis in order to validate the inputs and outcomes of our models with observed data, because the 'steady state' and life history assumptions used as a starting point in Ecosim might lead to tenuous extrapolations when moved far from 'equilibrium' (Plagányi \& Butterworth 2004). To address the risk of errors in the choice of representative diet composition when aggregating functional groups, we carefully selected the key species of each of our aggregated trophic groups, based on local documentation of the abundance and trophic importance of the species. Moreover, for aggregated groups of cetaceans (beaked whales, dolphins), we calculated the diet as a weighted average of all species, based on their total consumption in the ecosystem. Additionally, because the level of confidence attached to the Ecosim predictions is in large part a product of the quality of the input data and the level of statistical testing (Morissette 2007), we put great effort into using the most robust approach, with the best available data, validation by local experts, and multiple levels of uncertainty analyses.

Our holistic view of ecosystem structure and functions allowed us to reveal some cases of beneficial predation by cetaceans on other trophic groups of the foodweb (Morissette et al. 2006). In general, large predators were positively impacted by the presence of cetaceans because they eat small schooling fish such as clupeids that are competing with all other species for plankton (phyto- and zooplankton) at the base of the foodweb. Similarly, killer whales positively impacted both local and foreign fisheries because they feed on dolphins, which are major predators of small fish that are also targeted by fisheries.

\section{Challenges associated with data scarcity}

As indicated above, the kind of data required for ecosystem modeling was limited in our study area, especially for cetacean species. Notably the lack of dedicated surveys and existing abundance estimates of cetaceans in Northwest Africa greatly hampered the estimation of cetacean biomass and consequently food consumption. However, the predicted density estimates used in our model seemed reasonable for most species given the range of observed densities in survey areas representing similar types of habitat (Morissette et al. 2009). The extremely high densities of humpback whales reported in a few areas around Africa were observed in coastal waters where this species is known to aggregate during its breeding season (Clapham 2002). Consequently, the presence of high densities (of humpback whales and other cetaceans) in the very coastal waters (where the majority of coastal fisheries occur) could be responsible for people concluding that whales may be eating valuable fishery resources in Northwest Africa. However, it is important to note that Northwest African waters represent a breeding ground for baleen whales, and that most species are seen in more coastal zones during this part of their life cycle (Perrin et al. 2002). Despite the fact that they can be seen in the same areas as where fisheries are operating, our results showed that even under different assumptions of whale abundances, their impact is likely to be minimal on fisheries' catches. Given that our study area also includes a large proportion of offshore water, the lower density estimate used in the model probably represents an appropriate average estimate. Even considering more than the coastal area, our biomass estimates for all cetacean species together are even higher than what was initially used by Samb \& Mendy (2004) for cetaceans in the Senegabian coastal ecosystem $\left(0.039 \mathrm{t} \mathrm{km}^{-2} \mathrm{yr}^{-1}\right.$ in the initial coastal model versus $0.079 \mathrm{t} \mathrm{km}^{-2} \mathrm{yr}^{-1}$ in our global model), and thus we do not think that using a larger offshore area underestimated the biomass of these species. Similarly, the highest density for fin whales has been reported from the Mediterranean where there is a resident population, which likely shows different aggregation and movement patterns than the North Atlantic populations (Notarbartolo-di-Sciara et al. 2003).

The Dakar workshop 'Whales and fish interactions: are great whales a threat to fisheries?' allowed us to incorporate all additional data and local expertise into the models, but despite this effort, were not able to alleviate the problem of general paucity of data available for the Northwest African ecosystem. Nevertheless, we do not expect our general results to dramatically change should new data become available.

Data scarcity is also a problem for most fish species in Northwest Africa (Morissette et al. 2009), and especially for species that are not commercially exploited. Moreover, the lack of detailed local time series data about fisheries catches and effort forced us to use an alternative source for catch trend data to fit our model. However, these indirectly deduced catch data time series available from the Sea Around Us website (Sea Around Us 2008) come with several caveats (R. Watson pers. comm.) as they are derived from a global model. 
In our case, this produced a mismatch in geographic scale, since we used biomass time series from the original EWE model, which were very local, and most of the time applied to a particular country, while our time series of catches (driving the Ecosim predictions) were from the Sea Around Us Project (SAUP) database and represented the whole area. Consequently, it was difficult to find a good fit between model predictions, indirectly derived fisheries catches, and biomass trends. Nonetheless, even though data are sparse, we were able to test variations about our basic assumptions and explore a wide range of possible scenarios, which in the end did not generate different patterns in terms of whales interacting with fisheries.

In conclusion, the approach we have outlined here provides a novel method to examine the trophic role of cetaceans in tropical areas, even in the face of complex and highly uncertain ecosystem models. In the past, decisions regarding the management of whale populations or marine ecosystems in tropical areas have been made based on poor or no scientific data. In such situations when science is lacking, local knowledge becomes very valuable. Our results provide a scientific foundation and starting point for future discussions about ecological characteristics of cetaceans and fish in the Northwest African ecosystem. Given the current data paucity for this region, our results show that whales are not a threat to fisheries in Northwest Africa, and that removing whales from the ecosystem would not lead to any measurable impact on fishery yield under a wide range of reasonable assumptions. Therefore, unless we significantly increase our knowledge of the different trophic compartments of the Northwest African ecosystem, we should be very careful regarding how we manage it, and the precautionary approach should be established.

Acknowledgements. We thank the Lenfest Ocean Program for supporting this research and I.L. Bamy, D. Gascuel, M. Laurans, and R. Watson, who made their data available for the construction of the model. Thanks to J.L. Melgo from Arizona State University, S. Kromann of the US National Marine Mammal Laboratory, and Arizona State University Librarians for their reference mining and technical assistance. Survey density estimates were extracted from the global marine mammal survey database compiled with the help of C. Stephenson, N. Quick, and F. Sharpe from CREEM, St. Andrews University, as part of the ERMC(S)/Sonar S2117/ SAFESIMM project funded by BAE Integrated System Technologies (Insyte). We also acknowledge the participants of the May 2008 workshop in Dakar entitled 'Whale and fish interactions: are great whales a threat to fisheries?' for providing input and comments on the methods and data used for the construction of this model. Finally, we are grateful for the support and insight provided by J.C. Brêthes, V. Christensen, D. Pauly, and C. Piroddi in model construction and analysis.

\section{LITERATURE CITED}

Alder J, Sumaila UR (2004) Western Africa: a fish basket of Europe past and present. J Environ Dev 13:156-178

Amorim P, Duarte G, Guerra M, Morato T, Stobberup KA (2004) Preliminary Ecopath model of the Guinea-Bissau continental shelf ecosystem (NW Africa). In: Palomares MLD, Pauly D (eds) West African marine ecosystems: models and fisheries impacts. Fish Cent Res Rep 12:95-112

Anderson EM, Lovvorn JR (2008) Gray whales increase feeding opportunities for avian benthivores. Mar Ecol Prog Ser 360:291-296

Armstrong AJ, Siegfried WR (1991) Consumption of Antarctic krill by minke whales. Antarct Sci 3:13-18

Aydin K, Mueter F (2007) The Bering Sea-a dynamic food web perspective. Deep-Sea Res II 54:2501-2525

Bas C (1993) Long-term variability in the food chains, biomass yields, and oceanography of the Canary Current ecosystem. In: Sherman K, Alesander DG, Gold BD (eds) Large marine ecosystems: stress, mitigation, and sustainability. Wiley-Blackwell, Washington, DC, p 94-103

Bax NJ (1998) The significance and prediction of predation in marine fisheries. ICES J Mar Sci 55:997-1030

Branch TA, Stafford KM, Palacios DM, Allison C and others (2007) Past and present distribution, densities and movements of blue whales Balaenoptera musculus in the Southern Hemisphere and northern Indian Ocean. Mammal Rev 37:116-175

Brodie PF (1977) Form, function and energetics of Cetacea: a discussion. In: Harrison RJ (ed) Functional anatomy of marine mammals. Vol 3. Academic Press, London, p 45-56

Busby L (2004) Vote buying at the International Whaling Commission. In: Transparency International (eds) Global corruption report 2004, special focus: political corruption. Pluto Press, London and Sterling, VA, p 87-88

Chavance P, Ba M, Gascuel D, Vakily M, Pauly D (eds) (2004) Pêcheries maritimes, écosystèmes et sociétés en Afrique de l'Ouest: un demi-siècle de changement. Actes du symposium international, Dakar, Sénégal, 24-28 juin 2002. Office des publications officielles des communautés Européennes, XXXVI, collection des rapports de recherche halieutique ACP-UE 15

Christensen V, Walters C (2004) Ecopath with Ecosim: methods, capabilities and limitations. Ecol Model 172:109-139

Christensen V, Walters CJ, Pauly D (2005) Ecopath with Ecosim: a user's guide. November 2005 edn. Fisheries Centre, University of British Columbia, Vancouver, BC

Clapham PJ (2002) Humpback whale-Megaptera novaeangliae. In: Perrin WF, Würsig B, Thewissen JGM (eds) Encyclopedia of marine mammals. Academic Press, San Diego, CA, p 589-592

Clapham PJ, Childerhouse S, Gales NJ, Rojas-Bracho L, Tillman MF, Brownell RL Jr (2007) The whaling issue: conservation, confusion and casuistry. Mar Policy 31:314-319

Corkeron PJ (2009) Marine mammals' influence on ecosystem processes affecting fisheries in the Barents Sea is trivial. Biol Lett 5:204-206

Corkeron PJ, Connor RC (1999) Why do baleen whales migrate? Mar Mamm Sci 15:1228-1245

Diallo I, Cissé I, Bah A (2004) Modèle trophique du système côtier du plateau continental Guinéen. In: Palomares MLD, Pauly D (eds) West African marine ecosystems: models and fisheries impacts. Fish Cent Res Rep 12:113-123

Estes JA, DeMaster DP, Doak DF, Williams TM, Brownell RL Jr (2007) Whales, whaling, and ocean ecosystems. University of California Press, Berkeley, CA

Fedoseev A (1970) Geostrophic circulation of surface waters 
on the shelf of north-west Africa. Rapp P-V Reùn Cons Int Explor Mer 159:32-37

Folkow LP, Haug T, Nilssen KT, Nordøy ES (2000) Estimated food consumption of minke whales (Balaenoptera acutorostrata) in Northeast Atlantic waters in 1992-1995. NAMMCO Sci Publ 2:65-81

> Gerber LR, Morissette L, Kaschner K, Pauly D (2009) Should whales be culled to increase fishery yield? Science 323: $880-881$

IWC (International Whaling Commission) (2004) Report of the modelling workshop on cetacean-fishery competition. J Cetacean Res Manag 6 (Suppl):413-426

IWC(2008) Symposium sur I'utilisation durable des ressources marines vivantes de la région Africaine, Rabat, 11 to 12 February 2008; originally made available at the request of the Republic of Guinea via Circular Communication IWC.CCG.672 of 26 February 2008

Jann B, Allen J, Carrillo M, Hanquet S and others (2003) Migration of a humpback whale (Megaptera novaeangliae) between the Cape Verde Islands and Iceland. J Cetacean Res Manag 5:125-129

Kaschner K (2004) Modelling and mapping of resource overlap between marine mammals and fisheries on a global scale. $\mathrm{PhD}$ dissertation, University of British Columbia, Vancouver

Katona S, Whitehead H (1988) Are cetaceans ecologically important? Oceanogr Mar Biol Annu Rev 26:553-568

Kenney RD, Scott GP, Thompson TJ, Winn HE (1997) Estimates of prey consumption and trophic impacts of cetaceans in the USA Northeast Continental Shelf ecosystem. J Northwest Atl Fish Sci 22:155-171

Komatsu M, Misaki S (2003) Whales and the Japanese: how we have come to live in harmony with the bounty of the sea. The Institute of Cetacean Research, Tokyo

Lockyer C (1981) Growth and energy budgets of large baleen whales from the southern hemisphere. In: FAO Fish Ser 5, Mammals in the sea. Vol 3. FAO United Nations, Rome, p 379-488

Mendy AN (2004) A trophic model of the Gambian continental shelf system in 1986. In: Palomares MLD, Pauly D (eds) West African marine ecosystems: models and fisheries impacts. Fish Cent Res Rep 12:81-94

Mora C, Myers RA, Coll M, Libralato S and others (2009) Management effectiveness of the world's marine fisheries. PLoS Biol 7:e1000131

Morissette L (2007) Complexity, cost and quality of ecosystem models and their impact on resilience: a comparative analysis, with emphasis on marine mammals and the Gulf of St. Lawrence. PhD dissertation, University of British Columbia, Vancouver, BC

Morissette L, Melgo JL, Kaschner K, Gerber L (2009) Food web models and data for studying the interactions between marine mammals and fisheries in the Northwest African Ecosystem. In: Morissette L, Melgo JL, Kaschner $\mathrm{K}$, Gerber L (eds) Modelling the trophic role of marine mammals in tropical areas: data requirements, uncertainty, and validation. Fish Cent Res Rep 17:6-52

Morissette L, Hammill MO, Savenkoff C (2006) The trophic role of marine mammals in the Northern Gulf of St. Lawrence. Mar Mamm Sci 22:74-103

Myers RA, Worm B (2003) Rapid worldwide depletion of predatory fish communities. Nature 423:280-283

Notarbartolo-di-Sciara G, Zanardelli M, Jahoda M, Panigada S, Airoldi S (2003) The fin whale, Balaenoptera physalus (L. 1758), in the Mediterranean Sea. Mammal Rev 33:105-150

Paine RT, Tegner MJ, Johnson EA (1998) Compounded perturbations yield ecological surprises. Ecosystems 1:535-545

Palomares MLD, Pauly D (eds) (2004) West African marine ecosystems: models and fisheries impacts. Fish Cent Res Rep 12

Pauly D, Christensen V (1995) Primary production required to sustain global fisheries. Nature 374:255-257

> Pauly D, Christensen V, Dalsgaard J, Froese R, Torres FC Jr (1998) Fishing down marine food webs. Science 279:860-863

Pauly D, Christensen V, Guénette S, Pitcher TJ and others (2002) Towards sustainability in world fisheries. Nature 418:689-695

Pauly D, Alder J, Bennett E, Christensen V, Tyedmers P, Watson R (2003) The future for fisheries. Science 302:1359-1361

Perrin WF, Würsig B, Thewissen JGM (eds) (2002) Encyclopedia of marine mammals. Academic Press, San Diego, CA

Plagányi ÉE, Butterworth DS (2004) A critical look at the potential of Ecopath with Ecosim to assist in practical fisheries management. Afr J Mar Sci 26:261-287

Punt AE, Butterworth DS (1995) The effects of future consumption by the Cape fur seal on catches and catch rates of the Cape hakes. 4. Modelling the biological interaction between Cape fur seals Arctocephalus pusillus pusillus and the Cape hakes Merluccius Capensis and M. paradoxus. S Afr J Mar Sci 16:255-285

Rice DW (1998) Marine mammals of the world: systematics and distribution (Spec Publ 4). Allen Press, Lawrence, KS

Samb B, Mendy AN (2004) Dynamique du réseau trophique de l'écosystème Sénégambien en 1990. In: Palomares MLD, Pauly D (eds) West African marine ecosystems: models and fisheries impacts. Fish Cent Res Rep 12:57-70

> Scheffer M, Carpenter S, Foley JA, Folke C, Walker B (2001) Catastrophic shifts in ecosystems. Nature 413:591-596

Sea Around Us (2008) A global database on marine fisheries and ecosystems. Available at www.seaaroundus.org

Sergeant DE (1969) Feeding rates of Cetacea. Fiskeridir Skr Ser Havunders 15:246-258

Sidi TM, Guénette S (2004) Modèle trophique de la ZEE mauritanienne: comparaison de deux périodes (1987 et 1998). In: Palomares MLD, Pauly D (eds) West African marine ecosystems: models and fisheries impacts. Fish Cent Res Rep 12:12-38

Springer AM, Estes JA, van Vliet GB, Williams TM, Doak DF, Danner EM Forney KA, Pfister B (2003) Sequential megafaunal collapse in the North Pacific Ocean; an ongoing legacy of industrial whaling? Proc Natl Acad Sci USA 100:12223-12228

Stanford R, Lunn K, Guénette S (2001) A preliminary ecosystem model for the Atlantic coast of Morocco in the mid1980s. In: Guénette S Christensen V Pauly D (eds) Fisheries impacts on North Atlantic ecosystems: models and analyses. Fish Cent Res Rep 9:314-344

Stobberup KA, Ramos VDM, Coelho ML (2004) Ecopath model of the Cape Verde coastal ecosystem. In: Palomares MLD, Pauly D (eds) West African marine ecosystems: models and fisheries impacts. Fish Cent Res Rep 12:39-56

Trites AW, Christensen V, Pauly D (1997) Competition between fisheries and marine mammals for prey and primary production in the Pacific Ocean. J Northwest Atl Fish Sci 22:173-187

Ulanowicz RE, Puccia CJ (1990) Mixed trophic impacts in ecosystems. Coenoses 5:7-16

Walters C, Christensen V, Pauly D (1997) Structuring dynamic models of exploited ecosystems from trophic massbalance assessments. Rev Fish Biol Fish 7:139-172

Weslawski JM, Hacquebord L, Stempniewicz L, Malinga M (2000) Greenland whales and walruses in the Svalbard food web before and after exploitation. Oceanologia 42:37-56

> Yodzis P (2001) Must top predators be culled for the sake of fisheries? Trends Ecol Evol 16:78-84

Submitted: May 18, 2009; Accepted: December 1, 2009

Proofs received from author(s): March 17, 2010 